\title{
Produção de mudas de batata-doce de baixo custo em diferentes substratos e níveis de enfolhamento de estacas
}

\author{
Eduardo Pradi Vendruscolo ${ }^{1}$, Angélica Pires Batista Martins ${ }^{1}$, Luiz Fernandes Cardoso \\ Campos $^{1}$, Daniel Cardoso Brandão ${ }^{1}$, Lucas Marquezan Nascimento ${ }^{1}$, Alexsander Seleguini ${ }^{2}$ \\ ${ }^{1}$ Escola de Agronomia, Universidade Federal de Goiás, Goiânia, Goiás, Brasil. E-mail: agrovendruscolo@ gmail.com, \\ angelicapires.agro@gmail.com, luizfernandescampos@hotmail.com, dcbarquitetura@gmail.com, mznlucas@outlook.com. \\ ${ }^{2}$ Universidade Federal do Triângulo Mineiro, Campus de Iturama, Iturama, Minas Gerais, Brasil. E-mail: aseleguini@gmail.com
}

Recebido: 18/01/2017; Aceito: 21/06/2017.

\section{RESUMO}

A batata-doce é um alimento que se destaca como importante fonte de energia e fonte alternativa de carboidratos em substituição à grãos e outros tubérculos. O cultivo rudimentar, através da utilização de ramos para propagação diretamente a campo, é usual e pode, no entanto, ser responsável por um baixo índice de sobrevivência das brotações. Neste aspecto, objetivou-se definir a melhor técnica para obtenção de mudas em ambiente protegido através da utilização de diferentes substratos e níveis de enfolhamento das estacas de batatadoce. Foi empregado o delineamento experimental inteiramente casualizado, em esquema fatorial 4 x 2 , sendo quatro substratos (água, solução nutritiva, substrato turfoso saturado com água e substrato turfoso saturado com solução nutritiva) e dois tipos de estaca (folha inteira e meia folha), dispostos em quatro repetições. Avaliaramse, primeiramente, o comprimento e o número de raízes nas brotações em cada tratamento. Posteriormente, foi avaliada a porcentagem de brotações emergidas, o número de folhas, a altura e o diâmetro das brotações, a massa seca de parte aérea e de raízes das brotações emergidas. Concluiu-se que a estaquia realizada diretamente em substrato turfoso com solução nutritiva utilizando estacas com folhas inteiras é uma alternativa de baixo custo e resulta em mudas de batata-doce com elevada qualidade.

Palavras-chave: Ipomoea batatas L., propagação, enraizamento, custo de produção.

\section{Sweet potato low-costs seedling production in different substrates and cuttings leafiness levels}

\begin{abstract}
Sweet potato is an important source of energy and can be used as an alternative source of carbohydrates, replacing grains and tubers. The crude cropping, through the use of spread directly branches to the field, it is usual and it may, however, be responsible for a lowest fixation of shoots. In this regard, the objective was to determine the best technique to obtain seedlings in greenhouses by using different substrates and leafiness levels of sweet potato cuttings. The completely randomized design in a $4 \times 2$ factorial scheme, four substrates (water, nutrient solution, saturated peat substrate with water and saturated peat substrate with nutrient solution) and two types of cuttings leafiness (whole leaf and half leaf), with four repetitions was used. The length and the number of roots in sprouts of each treatment were evaluated. Posteriorly, the percentage of emerged shoots, leaf number, height and diameter of the shoots, dry mass of shoots and roots of the shoots emerged were evaluated. It can be concluded that cutting done directly on peaty substrate with nutritive solution using cuttings with whole leaves is a low-cost alternative and results in high quality sweet potato seedlings.
\end{abstract}

Key words: Ipomoea batatas L., propagation, rooting, production cost. 


\section{Introdução}

A batata-doce (Ipomoea batatas (L.) Lam) é considerada importante fonte de carboidrato para a população mundial (SILVEIRA et al., 2007) principalmente na China, que é destaque no cenário mundial de produtores desta raiz tuberosa, atingindo uma produção correspondente a 78,35\% do montante global (FAO, 2017). Em alguns países, como o Brasil, onde a produção ultrapassa 500 mil toneladas (FAO, 2017), a batata-doce participa como um alimento alternativo na diversificação alimentar da população (RUKMANA, 1997; LASE et al., 2013), além de ser matéria prima para a indústria alimentícia, no desenvolvimento de massas, pães, bolos, biscoitos e etanol, por exemplo. (NASCIMENTO et al., 2013; PRANOTO et al., 2014; VIEIRA et al., 2016).

$\mathrm{O}$ fácil desenvolvimento vegetal e o rápido crescimento e alcance de produtividade são pontos favoráveis ao cultivo da batata-doce em uma vasta gama de ambientes; a produtividade pode variar entre vinte e quarenta toneladas por hectare de raízes tuberosas frescas (ZURAIDA; SUPRIYATI, 2001; ANDRADE JÚNIOR et al., 2012). Por outro lado, as ramas podem ser utilizadas na alimentação animal para a engorda e abate na produção frigorífica (FIGUEIREDO et al., 2012).

No Brasil, a produção de batata-doce é uma atividade lucrativa (MELO et al., 2009), realizada principalmente em propriedades de agricultura familiar cujo sistema de produção caracteriza-se como de baixa tecnologia, a começar pela propagação, onde o cultivo se inicia com o plantio de ramas (estacas) não enraizadas diretamente a campo. O plantio direto dessas estacas a campo favorece um alto índice de mortalidade devido à pouca reserva proveniente da seção do caule combinada com condições ambientais desfavoráveis ao enraizamento e, consequente, necessidade de replantio das mudas para obtenção de um adequado estande final de plantas (EMBRAPA, 1995). Nesse sentido, a obtenção de mudas pré-enraizadas por estaquia pode representar uma alternativa promissora para a obtenção de mudas com qualidade superior ou quando há pouco material propagativo (RÓS; NARITA, 2011).

Estudos desenvolvidos visando a propagação de batata-doce têm demostrando que a utilização de recipientes e substratos variados proporciona boas condições para o enraizamento e consequente formação de mudas de qualidade (BRUNE et al., 2005; RÓS et al., 2011). No entanto, faltam informações acerca dos valores empregados na produção de mudas via estaquia quando se consideram os insumos usados para esta finalidade.

Em complemento aos substratos devem ser avaliadas outras técnicas que melhorem o desempenho da muda durante a fase de enraizamento. Nesse sentido, a presença de folhas em diferentes níveis pode interferir sobre a qualidade do material obtido uma vez que o corte da folha pode interferir sobre os teores de auxina, hormônio atuante no desenvolvimento dos órgãos vegetais (TAIZ et al., 2017). Vignolo et al. (2014) em estudo com a cultura da amoreira-preta constataram que estacas contendo folhas apresentaram maior taxa de enraizamento e desenvolvimento dos órgãos aéreos e radiculares.

Tendo em vista a importância socioeconômica da batata-doce, o desenvolvimento deste trabalho teve como objetivo definir a melhor técnica para obtenção de mudas em ambiente protegido por meio da utilização de diferentes substratos e níveis de enfolhamento das estacas de batata-doce, avaliando-se características biométricas de desenvolvimento e custo de obtenção das mudas.

\section{Material e Métodos}

O experimento foi conduzido em ambiente protegido instalado na área experimental da Escola de Agronomia, da Universidade Federal de Goiás em Goiânia - GO, no período de 9 de setembro a 7 de outubro do ano 2015. A estrutura apresentava as seguintes características: modelo arco, possuindo área de $42 \mathrm{~m}^{2}$ e pé direito de quatro metros, além de laterais e a porção superior cobertas com plástico transparente. Visando a manutenção da umidade a estufa foi provida de um sistema de nebulização intermitente. Durante a condução do experimento as médias das temperaturas máximas e mínimas registradas foram de $35,8{ }^{\circ} \mathrm{C}$ e 26,2 ${ }^{\circ} \mathrm{C}$. As bandejas de polietileno de alta densidade utilizadas para a formação das mudas possuíam vinte e cinco células com capacidade para $20 \mathrm{ml}$ de substrato.

Adotou-se o delineamento inteiramente casualizado com os tratamentos dispostos no esquema fatorial $4 \mathrm{x} 2$ (substratos x nível de enfolhamento das estacas) com quatro repetições de cinco estacas. Os substratos estudados foram: água (AG), solução nutritiva $(\mathrm{SN})$, substrato turfoso saturado com água (AG+TU) e substrato turfoso saturado com solução nutritiva (SN+TU) e dois tipos de estaca, contendo cerca de $1 \mathrm{~cm}$ da rama principal, o pecíolo e a folha, retiradas da porção mediana de ramas tenras, pouco lignificadas; folha inteira e meia folha (Figura 1).

A solução nutritiva utilizada no estudo foi a solução hidropônica comercial Hidrogood ${ }^{\circledR}$, composta por: N $(10,00 \%), \mathrm{P}(9,00 \%), \mathrm{K}(28,00 \%), \mathrm{Ca}(18,00 \%), \mathrm{Mg}$ $(3,30 \%), \mathrm{S}(4,30 \%)$, Fe EDDHA $(6,00 \%)$, B $(0,06 \%)$, $\mathrm{Cu}(0,01 \%)$, Mo (0,0746\%), Mn (0,05\%) e Zn $(0,02 \%)$.

Nos tratamentos compostos por substratos líquidos, as estacas foram mantidas com suas bases submersas por cinco dias, sendo, após este período, transferidas para bandejas contendo substrato comercial turfoso. 
Para os tratamentos em que as estacas foram colocadas diretamente em substrato turfoso, o conjunto foi saturado por cinco dias em água ou solução nutritiva. Visando a padronização do experimento, foram utilizados $20 \mathrm{~mL}$ de água ou solução nutritiva por estaca.

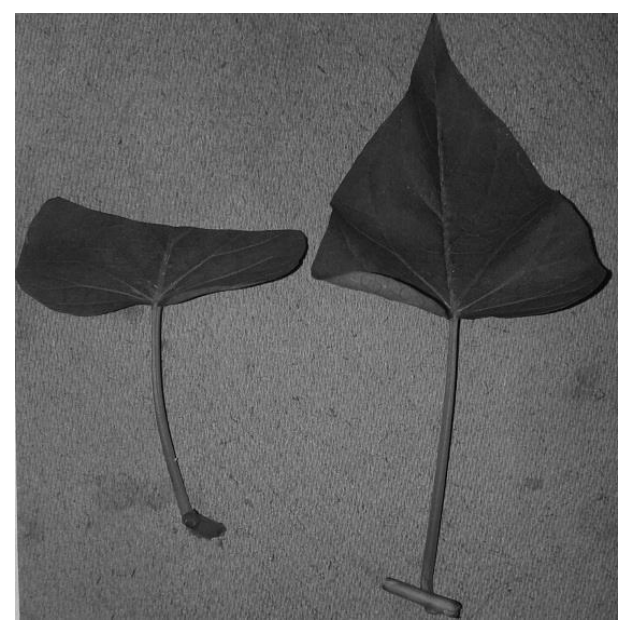

Figura 1 - Estacas de batata doce: meia folha (esquerda) e folha inteira (direita), Goiânia, GO, 2017.

Após o período inicial de cinco dias todos os tratamentos foram postos em similares condições experimentais. As estacas mantidas inicialmente apenas nos substratos líquidos foram transferidas para as bandejas contendo substrato turfoso; os tratamentos contendo as estacas em substrato saturado foram retirados do recipiente de saturação. Padronizados os tratamentos, todos receberam regas diárias.

As avaliações foram feitas em três etapas: aos cinco dias após a instalação do experimento, no momento da transferência das estacas do meio líquido para o substrato e na retirada do recipiente de saturação.

Foram avaliadas as variáveis de número e comprimento de raízes em cinco estacas tomadas aleatoriamente em cada solução, anteriormente à introdução do substrato turfoso. Após a padronização dos tratamentos, foram avaliados, semanalmente, o percentual de brotações, altura, diâmetro e número de folhas das brotações. Aos 28 dias após a padronização do experimento, as brotações foram separadas em raiz e parte aérea e postas para secar em estufa com circulação forçada de ar por três dias, à temperatura de $65{ }^{\circ} \mathrm{C}$ para determinação das fitomassas secas.

Para a análise estatística, devido à observação da baixa homogeneidade, os dados referentes ao comprimento de raízes, número de folhas das brotações, altura de brotação, massa seca de parte aérea e à massa seca de raízes foram transformados por raiz quadrada de $\mathrm{X}+0,5$. Os dados do percentual de brotos emergidos foram transformados por arcoseno da raiz quadrada de X sobre 100.
Os dados transformados, assim como os dados de porcentagem de brotações emergidas, altura, diâmetro e número de folhas das brotações foram submetidos à análise de variância e as médias comparadas pelo teste de Tukey a $5 \%$ e a $1 \%$ de probabilidade.

Para determinação do custo para produção de mudas, em cada tratamento foi calculado a quantidade de estacas (QDE), quantidade de substrato (QTSB), valor do substrato (VSB), quantidade de solução (QTSL), valor da solução (VSL) e o valor total gastos para a obtenção de cem mudas de batata-doce.

As cotações foram baseadas nos valores comerciais do substrato turfoso e da solução nutritiva vigentes no mês de maio do ano de 2017. O valor de $25 \mathrm{~kg}$ de substrato turfoso foi cotado, na cidade de Goiânia, a uma média de $\mathrm{R} \$ 15,00$ e o kit de preparo de mil litros de solução nutritiva foi cotado a $\mathrm{R} \$ 15,80$.

\section{Resultados e Discussão}

Aos cinco dias após a implantação do experimento verificou-se o enraizamento de todas as estacas. Este resultado está provavelmente, ligado à maturidade das ramas utilizadas. Estacas de ramas jovens, segundo Brune et al. (2005), apresentam melhores índices de enraizamento por apresentarem tecido menos rígido e menor tempo de contato com o solo o que, consequentemente, diminui as chances de contaminação por fungos ou danos causados pelo ataque de insetos.

Houve ausência de significância estatística para número de raízes por estaca, no entanto, para comprimento de raízes registrou-se superioridade dos tratamentos que consistiam da utilização da solução nutritiva (Tabela 1). O resultado está relacionado à oferta dos nutrientes que compõem a solução nutritiva pois a cultura da batata-doce é responsiva à alta fertilidade do meio, respondendo principalmente ao potássio, nitrogênio, fosforo, cálcio e magnésio, respectivamente (PRADO; CECÍLIO FILHO, 2016).

Tabela 1. Médias de número de raízes (NR) e comprimento de raízes (CR) de estacas de batata-doce cinco dias após a implantação do experimento. Goiânia-GO, 2017.

\begin{tabular}{lcc}
\hline Substratos & Número de raízes & $\begin{array}{c}\text { Comprimento de raízes } \\
(\mathrm{cm})\end{array}$ \\
\hline AG & 4,00 & $3,86 \mathrm{~b}^{* *}$ \\
$\mathrm{AG}+\mathrm{TU}$ & 4,80 & $2,99 \mathrm{~b}$ \\
$\mathrm{SN}$ & 3,70 & $7,85 \mathrm{a}$ \\
$\mathrm{SN}+\mathrm{TU}$ & 4,50 & $6,01 \mathrm{a}$ \\
\hline Enfolhamento & & \\
\hline Folha inteira & 4,45 & 5,13 \\
Meia folha & 4,05 & 5,23 \\
\hline CV\% & 17,17 & 15,57 \\
\hline
\end{tabular}

Médias seguidas de mesmas letras nas colunas não diferem entre si pelo teste de Tukey a $1 \%(* *)$ de probabilidade. AG: Água. SN: solução nutritiva. TU: substrato turfoso. 
Na primeira avaliação, sete dias após a transferência das estacas para as bandejas plásticas, observou-se maior emissão de brotações no tratamento combinado de substrato turfoso e solução nutritiva, sem que houvesse diferença significativa para a solução nutritiva. Para a altura verificou-se o incremento proporcionado pela solução nutritiva, isolada ou combinada ao substrato turfoso e pela presença da folha inteira na estaca (Tabela 2).

Novamente o resultado se relaciona à disponibilidade de nutrientes da solução. Vale ressaltar também que as raízes das estacas enraizadas diretamente no substrato turfoso foram mantidas intactas enquanto que as raízes das estacas mantidas em substrato líquido, ao serem transferidas para as bandejas, sofreram quebras. A perda do meristema radicular cessa o desenvolvimento da brotação, pois a citocinina, hormônio responsável pelo desenvolvimento das gemas laterais é produzida nessa porção e possui intensa atividade de divisão celular (RODRIGUES; KERBAUY, 2009; TAIZ et al., 2017).

Para a variável diâmetro de brotações emergidas foi observada a interação entre os fatores substrato e níveis de enfolhamento, em que, estacas de meia folha colocadas diretamente em AG+TU resultaram em maiores diâmetros em relação aos demais substratos e estacas com meia folha. Para estacas enraizadas diretamente em água houve superioridade de estacas contendo folhas inteiras. Os nutrientes presentes na solução proporcionaram melhor desenvolvimento dos tecidos vegetais, fornecendo os elementos necessários ao correto desenvolvimento celular. Porém, quanto ao desenvolvimento da brotação apenas em água, o resultado está relacionado aos maiores teores de auxinas produzidas nas folhas inteiras que regulam o alongamento e a divisão celular dos brotos (TAIZ et al., 2017).

Foi verificada diferença entre o número de folhas emitidas nas brotações apenas para os diferentes substratos. O resultado está relacionado a não emissão de folhas pelas brotações de estacas inicialmente colocadas no substrato AG. A falta de nutrientes e os danos causados pela transferência das estacas para as bandejas acarretaram em atraso no desenvolvimento das brotações.

Duas semanas após a transferência das estacas para as bandejas plásticas observou-se comportamento semelhante em relação ao número de brotações emergidas e altura das brotações (Tabela 3 ).

No entanto, para a variável diâmetro de brotação verificou-se que estacas de meia folha submetidas aos tratamentos com solução nutritiva obtiveram desenvolvimento superior aos demais tratamentos, enquanto que para os dois tratamentos com a utilização de água houve superioridade das estacas de folha inteira (Tabela 3). Este fato está relacionado ao desenvolvimento radicular, proporcionado pela produção de maiores quantidades de auxinas nas folhas inteiras que possibilitou a absorção dos nutrientes dos substratos contendo a solução nutritiva.

Tabela 2. Médias da interação e dos fatores isolados de substratos e níveis de enfolhamento de estacas de batata-doce para percentual de brotos emergidos (PBE), altura de brotação (ALT), diâmetro de brotação (DIM) e número de folhas das brotações (NF) aos sete dias após a estaquia. Goiânia-GO, 2017.

\begin{tabular}{|c|c|c|c|}
\hline \multirow{3}{*}{ Substratos } & \multicolumn{3}{|c|}{ DIM (mm) } \\
\hline & \multicolumn{3}{|c|}{ Enfolhamento } \\
\hline & Folha inteira & \multicolumn{2}{|c|}{ Meia folha } \\
\hline $\mathrm{AG}$ & $1,46 \mathrm{aA} * *$ & \multicolumn{2}{|c|}{$0,00 \mathrm{cB}$} \\
\hline $\mathrm{AG}+\mathrm{TU}$ & $1,57 \mathrm{aB}$ & \multicolumn{2}{|c|}{$2,29 \mathrm{aA}$} \\
\hline $\mathrm{SN}$ & $1,76 \mathrm{aA}$ & \multicolumn{2}{|c|}{$1,69 \mathrm{bA}$} \\
\hline $\mathrm{SN}+\mathrm{TU}$ & $1,78 \mathrm{aA}$ & & $1,81 \mathrm{bA}$ \\
\hline $\mathrm{CV} \%$ & \multicolumn{3}{|c|}{13,75} \\
\hline Substratos & PBE (\%) & ALT (cm) & $\mathrm{NF}$ \\
\hline $\mathrm{AG}$ & $2,50 \mathrm{c}^{* *}$ & $0,15 \mathrm{c} * *$ & $0,00 \mathrm{~b}^{* *}$ \\
\hline $\mathrm{AG}+\mathrm{TU}$ & $12,50 \mathrm{c}$ & $1,68 \mathrm{~b}$ & $1,25 \mathrm{a}$ \\
\hline $\mathrm{SN}$ & $42,50 \mathrm{~b}$ & $2,37 \mathrm{ab}$ & $1,34 \mathrm{a}$ \\
\hline $\mathrm{SN}+\mathrm{TU}$ & $72,50 \mathrm{a}$ & $2,72 \mathrm{a}$ & $1,46 \mathrm{a}$ \\
\hline \multicolumn{4}{|l|}{ Enfolhamento } \\
\hline Folha inteira & $33,75 a$ & $1,97 a^{*}$ & 1,03 \\
\hline Meia folha & $31,25 \mathrm{a}$ & $1,50 \mathrm{~b}$ & 1,00 \\
\hline CV\% & 16,89 & 12,64 & 12,39 \\
\hline
\end{tabular}

Médias seguidas de mesmas letras, minúsculas nas colunas e maiúsculas nas linhas, não diferem entre si pelo teste de Tukey a 5\% (*) ou a $1 \%(* *)$ de probabilidade. AG: Água. SN: solução nutritiva. TU: substrato turfoso. 
Tabela 3. Médias da interação e dos fatores isolados de substratos e níveis de enfolhamento de estacas de batata-doce para percentual de brotos emergidos (PBE), altura de brotação (ALT), diâmetro de brotação (DIM) e número de folhas das brotações (NF) quatorze dias após a estaquia. Goiânia-GO, 2017.

\begin{tabular}{|c|c|c|c|c|}
\hline \multirow{3}{*}{ Substratos } & \multicolumn{2}{|c|}{ DIM (mm) } & \multicolumn{2}{|c|}{$\mathrm{NF}$} \\
\hline & \multicolumn{4}{|c|}{ Enfolhamento } \\
\hline & Folha inteira & Meia folha & Folha inteira & Meia folha \\
\hline AG & $1,80 \mathrm{aA}^{* *}$ & $0,00 \mathrm{cB}$ & $2,00 \mathrm{aA}^{* *}$ & $0,00 \mathrm{bB}$ \\
\hline $\mathrm{AG}+\mathrm{TU}$ & $1,72 \mathrm{aA}$ & $1,33 \mathrm{bB}$ & $1,67 \mathrm{aA}$ & $2,25 \mathrm{aA}$ \\
\hline SN & $1,86 \mathrm{aA}$ & $1,93 \mathrm{aA}$ & $1,38 \mathrm{aA}$ & $1,81 \mathrm{aA}$ \\
\hline $\mathrm{SN}+\mathrm{TU}$ & $2,06 \mathrm{aA}$ & $2,03 \mathrm{aA}$ & $1,89 \mathrm{aA}$ & $1,98 \mathrm{aA}$ \\
\hline CV\% & \multicolumn{2}{|c|}{12,80} & \multicolumn{2}{|c|}{13,70} \\
\hline Substratos & \multicolumn{2}{|c|}{$\operatorname{PBE}(\%)$} & \multicolumn{2}{|c|}{ ALT $(\mathrm{cm})$} \\
\hline $\mathrm{AG}$ & \multicolumn{2}{|c|}{$2,50 \mathrm{c}^{* *}$} & \multicolumn{2}{|c|}{$0,40 \mathrm{c} * *$} \\
\hline $\mathrm{AG}+\mathrm{TU}$ & \multicolumn{2}{|c|}{$15,00 \mathrm{bc}$} & \multicolumn{2}{|c|}{$1,80 \mathrm{~b}$} \\
\hline $\mathrm{SN}$ & \multicolumn{2}{|c|}{$37,50 \mathrm{~b}$} & \multicolumn{2}{|c|}{$3,23 \mathrm{a}$} \\
\hline $\mathrm{SN}+\mathrm{TU}$ & \multicolumn{2}{|c|}{$65,00 \mathrm{a}$} & \multicolumn{2}{|c|}{$3,18 \mathrm{a}$} \\
\hline \multicolumn{5}{|l|}{ Enfolhamento } \\
\hline Folha inteira & \multicolumn{2}{|c|}{31,25} & \multicolumn{2}{|c|}{$2,66 a^{* *}$} \\
\hline Meia folha & \multicolumn{2}{|c|}{28,75} & \multicolumn{2}{|c|}{$1,64 b$} \\
\hline $\mathrm{CV} \%$ & \multicolumn{2}{|c|}{21,47} & \multicolumn{2}{|c|}{10,63} \\
\hline
\end{tabular}

Médias seguidas de mesmas letras, minúsculas nas colunas e maiúsculas nas linhas, não diferem entre si pelo teste de Tukey a 5\% (*) ou a 1\% (**) de probabilidade. AG: Água. SN: solução nutritiva. TU: substrato turfoso.

Para o número de folhas das brotações houve interação entre as variáveis estudadas. As estacas de meia folha submetidas ao tratamento com água em substituição ao substrato não apresentaram emissão de folhas nas brotações, diferindo dos demais tratamentos. (Tabela 3). O resultado está relacionado com a falta de nutrientes no substrato pois estes compõem e possibilitam o desenvolvimento dos órgãos vegetais (PRADO, 2008; TAIZ et al., 2017).

Aos vinte e um dias houve a estabilização da emergência de brotações, mantendo-se o comportamento observado nas demais avaliações (7 e 14 dias). O tratamento contendo solução nutritiva e substrato turfoso sobressaiu em relação aos tratamentos contendo apenas água, porém não diferindo do tratamento composto apenas pela solução nutritiva.

Para a altura das brotações, houve superioridade de todos os tratamentos sobre o tratamento que utilizou apenas a água como substrato para o enraizamento, indicando que mesmo em baixos teores, os nutrientes presentes no substrato turfoso comercial podem ter influenciado positivamente o desenvolvimento das brotações. A proximidade dos valores de diâmetro e número de folhas das brotações de estacas enraizadas em substrato turfoso e água e dos tratamentos contendo solução nutritiva também são indícios da utilização de nutrientes presentes no substrato turfoso (Tabela 4).

Quatro semanas após a transferência das estacas para as bandejas plásticas, observou-se maior desenvolvimento das brotações de estacas enraizadas em solução nutritiva, combinada ou não com o substrato turfoso, em relação à altura das brotações. Para o diâmetro das brotações, observou-se superioridade apenas para estacas enraizadas em solução nutritiva combinada ao substrato turfoso. Mais uma vez observa- se que o resultado está relacionado aos maiores teores de nutrientes presentes na solução nutritiva disponíveis à planta. Para número de folhas, observou-se que brotações advindas de estacas submetidas ao enraizamento apenas em água apresentaram o menor nível de enfolhamento em relação aos demais tratamentos (Tabela 5).

Menor nível de enfolhamento observado na Tabela 5 se deve à menor concentração de nutrientes como potássio, nitrogênio, fósforo, cálcio, magnésio, entre outros responsáveis pela constituição dos órgãos vegetais e manutenção das funções fisiológicas (PRADO, 2008), fato que culminou na morte das brotações. A combinação da solução nutritiva e do substrato turfoso proporcionou maior massa seca de parte aérea nas brotações provenientes de estacas mantidas com a folha inteira. No tratamento com nível de enfolhamento de meia folha houve diferença significativa apenas em relação às estacas enraizadas em água, pois as mesmas não produziram brotações (Tabela 6). Neste caso, as folhas podem servir como fonte de nutrientes para as novas brotações e ao ser realizado o corte parcial da folha também se diminuem os estoques de nutrientes, energia fotossintética e os teores de auxinas, responsáveis pela divisão e alongamento das células da brotação (TAIZ et al., 2017).

Diante dos resultados, é possível afirmar que na fase de formação das mudas, estacas de batata-doce apresentam acentuada resposta à adubação; fato também verificado por Rós et al. (2011), ao aplicar doses crescentes de adubo de liberação lenta observaram incrementos lineares do número e da produção de massa seca de folhas até os 28 dias após o plantio de porções apicais de ramas, com dois nós. 
Tabela 4. Médias da interação e dos fatores isolados de substratos e níveis de enfolhamento de estacas de batata-doce para percentual de brotos emergidos (PBE), altura de brotação (ALT), diâmetro de brotação (DIM) e número de folhas das brotações (NF) vinte e um dias após a estaquia. Goiânia-GO, 2017.

\begin{tabular}{|c|c|c|c|c|c|c|}
\hline \multirow{3}{*}{ Substratos } & \multicolumn{2}{|c|}{ ALT $(\mathrm{cm})$} & \multicolumn{2}{|c|}{ DIM (mm) } & \multicolumn{2}{|c|}{$\mathrm{NF}$} \\
\hline & \multicolumn{6}{|c|}{ Enfolhamento } \\
\hline & Folha inteira & Meia folha & Folha inteira & Meia folha & Folha inteira & Meia folha \\
\hline $\mathrm{AG}$ & $1,40 \mathrm{bA}^{*}$ & $0,00 \mathrm{bB}$ & $0,60 \mathrm{cA}^{* *}$ & $0,00 \mathrm{bB}$ & $2,00 \mathrm{abA}^{* *}$ & $0,00 \mathrm{bB}$ \\
\hline $\mathrm{AG}+\mathrm{TU}$ & $3,03 \mathrm{aA}$ & $2,78 \mathrm{aA}$ & $1,78 \mathrm{bA}$ & $1,81 \mathrm{aA}$ & $1,67 \mathrm{abB}$ & $2,75 \mathrm{aA}$ \\
\hline SN & $3,59 \mathrm{aA}$ & $2,94 \mathrm{aA}$ & $1,86 \mathrm{bA}$ & $1,95 \mathrm{aA}$ & $1,38 \mathrm{bA}$ & $1,75 \mathrm{aA}$ \\
\hline $\mathrm{SN}+\mathrm{TU}$ & $4,32 \mathrm{aA}$ & $3,68 \mathrm{aA}$ & $2,41 \mathrm{aA}$ & $1,99 \mathrm{aB}$ & $2,61 \mathrm{aA}$ & $2,38 \mathrm{aA}$ \\
\hline CV\% & \multicolumn{2}{|c|}{12,30} & \multicolumn{2}{|c|}{13,23} & \multicolumn{2}{|c|}{12,29} \\
\hline Substratos & \multicolumn{6}{|c|}{ PBE (\%) } \\
\hline $\mathrm{AG}$ & \multicolumn{6}{|c|}{$2,50 \mathrm{c}^{* *}$} \\
\hline $\mathrm{AG}+\mathrm{TU}$ & \multicolumn{6}{|c|}{$15,00 \mathrm{bc}$} \\
\hline $\mathrm{SN}$ & \multicolumn{6}{|c|}{$42,50 \mathrm{ab}$} \\
\hline $\mathrm{SN}+\mathrm{TU}$ & \multicolumn{6}{|c|}{$62,50 \mathrm{a}$} \\
\hline \multicolumn{7}{|l|}{ Enfolhamento } \\
\hline Folha inteira & \multicolumn{6}{|c|}{32,50} \\
\hline Meia folha & \multicolumn{6}{|c|}{28,75} \\
\hline CV\% & \multicolumn{6}{|c|}{18,17} \\
\hline
\end{tabular}

Médias seguidas de mesmas letras, minúsculas nas colunas e maiúsculas nas linhas, não diferem entre si pelo teste de Tukey a $5 \%(*)$ ou a $1 \%(* *)$ de probabilidade. AG: Água. SN: solução nutritiva. TU: substrato turfoso.

Tabela 5. Médias da interação e dos fatores isolados de substratos e níveis de enfolhamento de estacas de batata-doce para percentual de brotos emergidos (PBE), altura de brotação (ALT), diâmetro de brotação (DIM) e número de folhas das brotações (NF) vinte e oito dias após a estaquia. Goiânia-GO, 2017.

\begin{tabular}{|c|c|c|c|c|}
\hline \multirow{3}{*}{ Substratos } & \multicolumn{2}{|c|}{ ALT (cm) } & \multicolumn{2}{|c|}{ DIM (mm) } \\
\hline & \multicolumn{4}{|c|}{ Enfolhamento } \\
\hline & Folha inteira & Meia folha & Folha inteira & Meia folha \\
\hline $\mathrm{AG}$ & $1,85 \mathrm{bA}^{* *}$ & $0,00 \mathrm{cB}$ & $1,74 \mathrm{bA}^{* *}$ & $0,00 \mathrm{cB}$ \\
\hline $\mathrm{AG}+\mathrm{TU}$ & $2,57 \mathrm{bA}$ & $2,78 \mathrm{bA}$ & $1,75 \mathrm{bA}$ & $1,89 \mathrm{bA}$ \\
\hline $\mathrm{SN}$ & $4,01 \mathrm{aA}$ & $3,49 \mathrm{abA}$ & $1,86 \mathrm{bA}$ & $1,96 \mathrm{bA}$ \\
\hline $\mathrm{SN}+\mathrm{TU}$ & $4,93 \mathrm{aA}$ & $4,25 \mathrm{aA}$ & $2,44 \mathrm{aA}$ & $2,32 \mathrm{aA}$ \\
\hline CV\% & \multicolumn{2}{|c|}{17,95} & \multicolumn{2}{|c|}{10,58} \\
\hline Substratos & \multicolumn{2}{|c|}{ PBE (\%) } & \multicolumn{2}{|c|}{$\mathrm{NF}$} \\
\hline $\mathrm{AG}$ & \multicolumn{2}{|c|}{$5,00 \mathrm{~b}^{* *}$} & \multicolumn{2}{|c|}{$0,00 \mathrm{~b}^{* *}$} \\
\hline $\mathrm{AG}+\mathrm{TU}$ & \multicolumn{2}{|c|}{$15,00 \mathrm{~b}$} & \multicolumn{2}{|c|}{$2,42 \mathrm{a}$} \\
\hline $\mathrm{SN}$ & \multicolumn{2}{|c|}{$35,00 \mathrm{ab}$} & \multicolumn{2}{|c|}{$2,06 \mathrm{a}$} \\
\hline $\mathrm{SN}+\mathrm{TU}$ & \multicolumn{2}{|c|}{$60,00 \mathrm{a}$} & \multicolumn{2}{|c|}{$2,37 \mathrm{a}$} \\
\hline \multicolumn{5}{|l|}{ Enfolhamento } \\
\hline Folha inteira & \multicolumn{2}{|c|}{30,00} & \multicolumn{2}{|c|}{1,56} \\
\hline Meia folha & \multicolumn{2}{|c|}{34,00} & \multicolumn{2}{|c|}{1,86} \\
\hline CV\% & \multicolumn{2}{|c|}{33,24} & \multicolumn{2}{|c|}{16,77} \\
\hline
\end{tabular}

Médias seguidas de mesmas letras, minúsculas nas colunas e maiúsculas nas linhas, não diferem entre si pelo teste de Tukey a 5\% (*) ou a 1\% (**) de probabilidade. AG: Água. SN: solução nutritiva. TU: substrato turfoso.

Quando utilizadas estacas de folha inteira, as maiores produções de massa seca de raízes foram observadas em brotações previamente enraizadas em água e substrato turfoso combinado à solução nutritiva. Com relação às enraizadas em água, a falta de nutrientes pode ter estimulado a mobilização das reservas em prol do desenvolvimento radicular, a fim de aumentar a área radicular na busca por nutrientes. Em contrapartida, brotações anteriormente enraizadas em substrato turfoso combinado à solução nutritiva podem ter acumulado reservas suficientes para o desenvolvimento de ambas as partes vegetais, aérea e radicular.

Devido à ausência de brotações no tratamento para enraizamento de estacas com meia folha apenas em água, este foi significativamente diferente em relação aos demais substratos. A ausência de brotações também inferiu em diferença significativa quanto ao tipo de estaca utilizada. Diferenças significativas entre os níveis de enfolhamento de estacas utilizados foram observados para estacas enraizadas nos tratamentos contendo substrato turfoso combinado à água ou à solução nutritiva. No primeiro caso a superioridade de estacas com meia folha pode possivelmente, estar relacionada à falta de reservas nutritivas, resultando na busca por nutrientes. No segundo caso a presença da solução nutritiva no momento do enraizamento combinada à maior presença de reservas nas folhas resultou em desenvolvimento de ambas as partes das brotações.

Apesar das vantagens quanto ao desenvolvimento das mudas, deve-se tomar em consideração o fator econômico envolvido. Apesar dos estudos desenvolvidos para definição dos melhores tratamentos a serem aplicados na 
produção de mudas de diversas espécies, poucos são os que relevam o fator econômico.

O baixo custo observado inicialmente na produção de mudas via enraizamento em água pode ser atrativo, no entanto, o baixo percentual de mudas emergidas pode tornar esta opção pouco vantajosa ao produtor. A estaquia direta em substrato turfoso saturado com solução nutritiva pode representar uma opção mais viável ao produtor.
Estima-se, que para a obtenção de cem mudas enraizadas, há necessidade de maiores estandes iniciais de fragmentos da rama quando o enraizamento ocorre diretamente na água. Para esta situação, requer-se uma quantidade $66,7 \%, 85,7 \%$ e $91,7 \%$ maior de estacas em relação à utilização da água combinada ao substrato turfoso, da solução nutritiva e da combinação entre solução nutritiva e substrato turfoso, respectivamente (Tabela 7).

Tabela 6. Médias da interação entre substratos e níveis de enfolhamento de estacas de batata-doce para massa seca de parte aérea (MSPA) e massa seca de raízes (MSRZ) vinte e oito dias após a estaquia. Goiânia-GO, 2017.

\begin{tabular}{lcrrr}
\hline \multirow{2}{*}{ Substratos } & \multicolumn{3}{c}{ MSPA (mg) } & \multicolumn{2}{c}{ MSRZ (mg) } \\
\cline { 2 - 5 } & Folha inteira & Meia folha & Folha inteira & Meia folha \\
\cline { 2 - 5 } & $19,00 \mathrm{bA}^{*}$ & $0,00 \mathrm{bB}$ & $193,50 \mathrm{aA} * *$ & $0,00 \mathrm{bB}$ \\
AG & $28,75 \mathrm{bA}$ & $47,75 \mathrm{aA}$ & $41,25 \mathrm{bB}$ & $120,63 \mathrm{aA}$ \\
AG+TU & $32,13 \mathrm{bA}$ & $34,69 \mathrm{aA}$ & $58,62 \mathrm{bA}$ & $94,13 \mathrm{aA}$ \\
SN & $97,65 \mathrm{aA}$ & $74,30 \mathrm{aA}$ & $155,29 \mathrm{aA}$ & $76,11 \mathrm{aB}$ \\
SN+TU & & 28,02 & & 24,86 \\
\hline CV\% & & & & \\
\hline
\end{tabular}

Médias seguidas de mesmas letras, minúsculas nas colunas e maiúsculas nas linhas, não diferem entre si pelo teste de Tukey a $5 \%(*)$ ou a $1 \%(* *)$ de probabilidade. AG: Água. SN: solução nutritiva. TU: substrato turfoso.

Tabela 7. Quantidade de estacas (QDE), quantidade de substrato (QTSB), valor do substrato (VSB), quantidade de solução (QTSL), valor da solução (VSL) e o valor total gastos para a obtenção de cem mudas em cada substrato. Goiânia-GO, 2017.

\begin{tabular}{lcccccc}
\hline \multicolumn{1}{c}{ Substratos } & QDE & QTSB $(\mathrm{g})$ & VSB $(\mathrm{R} \$)$ & QTSL $(\mathrm{l})$ & VSL $(\mathrm{R} \$)$ & TOTAL $(\mathrm{R} \$)$ \\
\hline AG & 2000,00 & 40,00 & 66,67 & 0,00 & 0,00 & 66,67 \\
AG+TU & 667,00 & 13,33 & 22,22 & 0,00 & 0,00 & 22,22 \\
SN & 286,00 & 5,71 & 9,52 & 5,71 & 0,09 & 9,61 \\
SN+TU & 167,00 & 3,33 & 5,56 & 3,33 & 0,05 & 5,61 \\
\hline
\end{tabular}

AG: Água. SN: solução nutritiva. TU: substrato turfoso.

A necessidade de se utilizar maior quantidade de estacas também influi sobre os gastos monetários, pois uma grande quantidade de estacas demanda aumento da quantidade de substrato utilizado. Assim, devido à menor taxa de brotação das estacas enraizadas em água, os ganhos podem chegar a $\mathrm{R} \$ 44,45, \mathrm{R} \$ 57,09$ e $\mathrm{R} \$$ 61,06 para cada cem mudas produzidas utilizando os tratamentos: água combinada ao substrato turfoso; solução nutritiva; combinação entre solução nutritiva e substrato turfoso, respectivamente.

A escassez de estudos acerca da cultura da batata doce e de seus entraves durante o ciclo produtivo não refletem a relevância socioeconômica dessa hortaliça. Estudos abrangentes sobre os tratos culturais devem ser o foco para futuras pesquisas, a fim de contribuir com a renda do produtor e com a qualidade do produto final.

\section{Conclusões}

A estaquia realizada diretamente em substrato turfoso com solução nutritiva utilizando estacas com folhas inteiras é uma alternativa de baixo custo e resulta em mudas de batata-doce com elevada qualidade.

\section{Agradecimentos}

A Capes pela concessão da bolsa de doutorado ao primeiro autor.

\section{Referências Bibliográficas}

ANDRADE JÚNIOR, V. C.; VIANA, D. J. S.; PINTO, N. A.; RIBEIRO, K. G.; CRISTINA, R. Características produtivas e qualitativas de ramas e raízes de batata-doce. Horticultura Brasileira, Brasília-DF, v. 30, n. 4, p. 584-589, 2012.

BRUNE, S.; SILVA, J. B. C.; FREITAS, R. A. Novas técnicas de multiplicação de ramas de batata-doce. Brasília-DF: Embrapa Hortaliças, 2005. 8 p. (Circular Técnica, 39).

EMBRAPA. EMPRESA BRASILEIRA DE PESQUISA AGROPECUÁRIA. Cultivo da batata-doce (Ipomoea batatas (L.) Lam). Brasília-DF: Ministério da Agricultura, Abastecimento e Reforma Agrária, 1995. 10 p. (Instruções Técnicas, 7).

FAO. FOOD AND AGRICULTURE ORGANIZATION OF THE UNITED NATIONS. Crops. 2017. In: FAOSTAT. Disponível em: 〈http://www.fao.org/faostat/en/\#data/QC〉. Acesso em: 20 mai. 2017. 
FIGUEIREDO, J. A.; PEREIRA, R., RIBEIRO, K.; VIANA, D.; NEIVA, I. Avaliação de silagens de ramas de batata-doce. Horticultura Brasileira, Brasília-DF, v. 30, n. 4, p. 708-712, 2012.

LASE, V. A.; JULIANTI, E.; LUBIS, L. M. Bihon type noodles from heat moisture treated starch of four varieties of sweet potato. Jurnal Teknologi dan Industri Pangan, Bogor-ID, v. 24, n. 1, p. 89-96, 2013.

MELO, A. S.; COSTA, B. C.; BRITO, M. E. B.; NETTO, A. O. A.; VIÉGAS, P. R. A. Custo e rentabilidade na produção de batata-doce nos perímetros irrigados de itabaiana, Sergipe. Pesquisa Agropecuária Tropical, Brasília-DF, v. 39, n. 2, p. 119-123, 2009.

NASCIMENTO, K. D. O.; ROCHA, D. G. C. M.; SILVA, E. B.; BARBOSA JÚNIOR, J. L.; BARBOSA, M. I. M. J. Caracterização química e informação nutricional de fécula de batata-doce (Ipomoea batatas L.) orgânica e biofortificada. Revista Verde de Agroecologia e Desenvolvimento Sustentável, Pombal-PB, v. 8, n. 1, p. 132-138, 2013.

PRADO, R. M. Nutrição de plantas. São Paulo-SP: Editora Unesp, 2008. 407 p.

PRADO, R. M.; CECÍlIO FILHO, A. B. Nutrição e adubação de hortaliças. Jaboticabal-SP: FCAV/CAPES, 2016. 600p.

PRANOTO, Y.; RAHMAYUNI, H.; RAKSHIT, S. K. Physicochemical properties of heat moisture treated sweet potato starches of selected Indonesian varieties. International Food Research Journal, Serdang-MY, v. 21, n. 5, p. 2121$2128,2014$.

RODRIGUES, M. A.; KERBAUY, G. B. Meristemas: fontes de juventude e plasticidade no desenvolvimento vegetal. Hoehnea, São Paulo-SP, v. 36, n. 4, p. 525-549, 2009.
RÓS, A. B.; ARAÚJO, H. S.; NARITA, N.; TAVARES FILHO, J. Uso de fertilizante e tempo de permanência de mudas de batata-doce produzidas em bandejas. Pesquisa Agropecuária Brasileira, Brasília-DF, v. 46, n. 8, p. 845-851, 2011.

RÓS, A. B.; NARITA, N. Produção de mudas de batata-doce a partir de poucas plantas matrizes. Brazilian Journal of Agricultural Sciences/Revista Brasileira de Ciências Agrárias, Recife-PE, v. 6, n. 1, p. 85-89, 2011.

RUKMANA, R. Sweet Potato: Cultivation and Postharvest. Yogyakarta-ID: Kanisius Press, 1997. 68 p.

SILVEIRA, M. A.; ANDRÉ, C. M. G.; ALVIM, T. C.; DIAS, L. E.; TAVARES, I. B.; SANTANA, W. R.; SOUZA, F. R. A cultura da batata-doce como fonte de matéria-prima para a produção de etanol. Palmas-TO: Universidade Federal do Tocantins, 2007. 45 p. (Boletim Técnico).

TAIZ, L.; ZEIGER, E.; MOLLER, I. M.; MURPHY, A. Fisiologia e desenvolvimento vegetal. 6. ed. Porto AlegreRS: Artmed, 2017. 888 p.

VIEIRA, A. D.; MIRANDA, V. C.; ALVES, A. F.; TAVARES, A. T.; MOMENTÉ, V. G. Agronomic evaluation of clones of sweet potato with potential for ethanol production. Applied Research \& Agrotechnology, v. 8, n. 1, p. 69-74, 2016.

VIGNOLO, G. K.; PICOLOTTO, L.; GONÇALVES, M. A.; PEREIRA, I. D. S.; ANTUNES, L. E. C. Presença de folhas no enraizamento de estacas de amoreira-preta. Ciência Rural, Santa Maria, v. 44, n. 3, p. 467-472, 2014.

ZURAIDA, N.; SUPRIATI, Y. Usahatani ubi jalar sebagai bahan pangan alternatif dan diversifikasi sumber karbohidrat. Buletin Agrobio, Bogor-ID, v. 4, n. 1, p. 13-23, 2001. 